Cognition and the City special issue, to be published by The Built Environment.

The city is the map: exosomatic memory, shared cognition and a possible mechanism to account for social evolution.

Alan Penn

Abstract

One role of the city is often overlooked. This is its role in providing a common setting for social action. This paper reviews research into the geometry and topology of urban built space and the way that these configurational structures appear to be appropriated for human individual and social purposes. It links economic, cultural and political domains of social action to the physical and spatial structure of cities. In doing so it points to those aspects of individual perception and cognition that must logically be assumed to be common between individuals, and so form a basis for the social. It proposes, following Bratman (1987), that our individual actions involve at least three distinct psychological dimensions: the beliefs we hold about the world we inhabit are substantially cognitive; our desires are affective or emotional; and our immediate intentions are guided by both desire and our beliefs about the world, for the most part through apparently rational behaviour. If on occasion our behaviour appears less than rational, this can usually be traced back to a misapprehension about the nature of the world a cognitive deficit - to the driving motivation being emotional, or to the apparently irrational outcomes of system dynamics involving feedback processes, for example in the operation of markets. It concludes by suggesting that an important part of our cognitive apparatus lies outside our bodies in the morphology of the environments we build and the way that we appropriate these for use. Since the construction and use of the built environment is distributed amongst many actors in a population, it is suggested that the environment of the city itself becomes a part of the shared cognitive capacity for communities, allowing these to behave as if a single organism from a cognitive point of view. This offers a possible mechanism to account for the rapid pace of human social evolution over the last 10,000 years.

Amongst the more intriguing aspects of human history is that while our genetic make-up has not changed substantially in over a hundred thousand years, the social and technological world we inhabit today is so different to that of just a few years ago. This suggests that Darwinian evolution, subsequent to the emergence of homo sapiens, accounts for little of contemporary human progress; an account of progress must instead appeal to social, cultural and technological evolution. Let me pose the question like this: how is it that despite the fact that individuals in society live for just a few years, on occasion social forms, states and cultures can persist for centuries? At the same time, how is it that our social and cultural conditions can appear to develop rapidly and to change beyond recognition within just a few years? What mechanisms lie behind the diversity of social and cultural forms we observe and the way these are conserved and generated over time? There have of course been numerous attempts in the sociological and anthropological literature to catalogue social forms and to develop a theoretical basis for the field, however I would suggest that it is currently in an essentially pre-Darwinian and pre-Mendelian state in theoretical terms. No full and persuasive account has yet been made to suggest a mechanism for social evolution.

Perhaps the most striking change over this period is in terms of the scale of the human group or polity. While early humans are thought to have lived in small bands or family groups numbering perhaps a few dozen individuals, cities today comprise tens of millions and the largest states such as China and India number well over a billion people. The scale of the polity or state seems to have gone hand in hand with technological progress, with each making the other possible: technological innovations support larger and denser populations, and large, dense populations speed innovation (Korotayev, 2006). It seems to be no coincidence that this feedback loop, and then the onset of rapid human progress, can be dated back to the first built settlements in the Anatolian plateau about ten thousand years ago. These came before writing and currency, and probably predate settled arable agriculture. Built settlements appear to have been a catalyst for a series of very rapid advances in society.

This paper argues that the invention of the building and the settlement created a new stratum of cognitive machinery, outside the individual brain and body, and ultimately it is this that 
has allowed a collective intelligence to develop, which in turn accounts for social, cultural and technological evolution. There is a growing body of literature on the extended mind to support the notion that we recruit aspects of our environment to support cognitive function. See for example Andy Clark \& David Chalmers' (1998) account of the extended mind, and David Kirsh (2011a, b) on the use of external artefacts to support cognitive processes. Merlin Donald, in his evolutionary account of the development of language, proposes that externalised skills in, for example, tool making as well as other material cultures, are of direct cognitive importance (Donald, 2017). This has been argued with regard to cities by Portugali (2011) Haken and Portugali (2015), as well as Portugali in this volume.

This paper first reviews some of what is known about the long history of human progress and the development of modern society. Next it describes the way in which built space might be thought to affect social interaction and transaction, and it uses this to propose the ways in which human cognition might recruit the external environment to support the evolution of social forms. Built space is described as a kind of universal that applies to all people and holds various affordances that humans appropriate in specific ways. For example, we cannot fly, and so in general terms we are rooted to the ground plane. We cannot see through or move through walls, and so the construction and configuration of walls has direct effects on both movement and communication. We have forward facing vision, and this affects how we move and locate ourselves relative to objects and other beings in our environment. These constraints are so basic that in general we overlook them; however, it can be argued that the discovery that built form affects social interaction marked a turning point in human history. We progressed from appropriating the affordances of the environment as we found it, to shaping those affordances to suit our social needs. This was the point at which human kind gained a mechanism by which social structures could not only reproduce, and so outlast an individual lifespan, but also generate new social forms so that these could evolve in a controlled and reproducible way. Since the buildings we construct and the way that these are used, is for the main part, a product of large numbers of different people collaborating, competing and interacting, the form it takes is a direct result of the social structure and economy of the community that produced it. This has two primary components, a spatial configuration produced by the construction of buildings, and a pattern of locations of functional land uses. Since the configuration of space and the disposition of functional uses in space affects the way that members of a society move on their daily routines, it affects directly the probability of encounter between individuals. This in turn affects the social network of 'who knows whom'. And lastly, since this mechanism is 'exosomatic', lying outside any individual body, it is shared amongst and acts upon all members of a community.

\section{A brief history of human progress}

The 'out of Africa' hypothesis holds that anatomically modern humans emerged in northern Africa around 300,000 years ago and migrated in a series of waves around the world between 100,000 years and 60,000 years ago. They appear to have migrated as bands of foragers or hunter gatherers to settle in different regions of the globe. Here they met with, and evidence suggests, interbred with and subsumed, earlier hominid sub-groups such as the Neanderthal and Denisovan which had themselves migrated out of Africa in earlier epochs. This theory is supported by both archaeological evidence and analysis of mitochondrial DNA which allows estimates to be made of when different groups must have divided, moved and interbred (Dalén et al., 2012; Cooper \& Stringer, 2013). Whatever the detail of this history it is evident that in the last 100,000 years modern humans have become one of the most widespread and successful of all species. 
A number of factors have been suggested as contributing to that success. Bipedalism freed the hands for tool making and tool use, as well as for carrying infants and other loads over distance. The size of a human skull resulted in early birth of a dependant infant, something which itself required the development of an extended caring social group. There is an alternative hypothesis that holds that social caring came first and was the primary force in selecting for higher intelligence, and thus the cause rather than the result of increasing skull size (Humphries, 1976; Jolly, 1966). A wide diet allowed considerable resilience and ability to adapt to different environments, but also involved both foraging and predation, activities which make different requirements of the social group and which therefore benefit from plasticity of social group formation. Language facilitated sophisticated group interaction, which gave a considerable advantage in both activities. While all of these were probably features of earlier human species as well, in homo sapiens they seem to have reached higher levels of development.

I suggest that two specific cognitive competences seem to underpin human success. First, the development of empathy. This is the ability to imagine oneself in another being's place, to see things from another's point of view and to read and interpret the behaviours and body language of others by imagining what they must be feeling. It is likely that this was invaluable both as predators who were better able to understand and predict the behaviour of prey, and as social collaborators who could therefore better interact with, and care for colleagues.

Second, imagination. This can be thought of as a development of empathy, but without the need for there to be another being with which to empathise. Humans can imagine what it would be like, and what we would feel, under different circumstances to our current reality. The ability to imagine has three direct consequences: we can imagine agency as an attribute of inanimate objects, and so develop both tools and symbol systems; second, we can imagine causal relationships and so develop rational hypotheses about how the world might work, as well as how we might intervene to change that world; and third, we can imagine in order to plan, and so coordinate our behaviour and that of other members of our group to achieve desired ends.

Neither empathy nor imagination are the sole preserve of humans, but in homo sapiens they appear to have developed in such a way that sophisticated social, technological and cultural structures have arisen. I propose that three factors may have been instrumental in this. First, human language is symbolic in that it makes use of an arbitrary association between phonemes and meanings. Symbolic systems also exhibit 'displacement', in that they are not tied to current phenomena in the world but can be used to discuss abstractions and fictions (Bohn et al, 2015). Displacement allowed abstractions to be shared and so made possible both religious and scientific thought. It has been argued that religion gave a higher purpose to life than merely perpetuation of the individual's genes, and so supported the extension of the polity beyond the family group (Fukuyama, 2011). Archaeological evidence exists for art which date back over 40,000 years in cave paintings in Europe and possibly up to 500,000 years for decorated clam shells in Java from the Homo Erectus period (Joordens et al, 2015). These suggest that the capacity to make use of acoustic or physical phenomena in the world to externalise, and so to share with others, an individual's thoughts and reasoning, were a distinguishing feature of human society from the earliest times.

Second, the structures of story-telling seem likely to have developed very early in pre-history. Marie-Laure Ryan argues that it is the ability to imagine 'possible worlds' that gives structure 
and meaning to fictional narrative. She proposes that the listener is an active participant in story-telling who imagines 'possible worlds' for the protagonists, which are then fulfilled, or not, as the narrator proceeds. Each new piece of information adds to the listener's understanding and must be reconciled with their hypothetical 'possible world'. It is by active hypothesis formulation, testing against the successive episodes of a narrative on the part of the listener, and reformulation, through which Ryan suggests, meaning is created for the listener. This casts narrative as a social and relational phenomenon in which the narrator and their audience, as well as the protagonists of the story, are all active participants. The audience is as much a meaning maker as the author and brings to the exercise their own knowledge and experience.

Third, the use of physical objects as tools predates homo sapiens, involving the appropriation of the physical affordances of an object to a task at hand, as well as the adaptation of those affordances to better suit our needs. The important notion here is that the human ability to interact with a physical object to turn it to use for a specific purpose, to pick up a rock to use as a hammer, for example, and for that object to become an extension of our body, has its counterpart in the cognitive world of symbol systems and meanings. A written note becomes an extension of our memory, or an architectural sketch becomes a tool for thinking through the consequences of some set of design propositions. This experimental engagement with objects and phenomena (fire for example), in the physical and natural world, when coupled to hypothetico-deductive reasoning and the symbolic manipulation of abstract relations, eventually through mathematical notation, can be argued to be central to the development of modern science, which in turn has enabled the explosive growth of modern technology.

All three of these seem likely to have been important factors in human development from the prehistoric origins of homo sapiens, however, there was a step change in human progress that appears to have started around 10,000 years ago. It seems likely that a number of factors came together at around this time. Climatic changes from the Pleistocene to the Holocene made settled arable agriculture possible for the first time with a much more stable period of seasonal climate (Richerson et al, 2001). However, within a just a few thousand years all the apparatus of a modern society and state appeared and in the last 500 years those of western science and technology. What happened that oversaw such a rapid evolution of human social and cultural forms?

\section{The Anatolian discovery}

The hypothesis presented here is that the catalyst might have been the discovery of a very basic effect of built form on the potential for social interaction. At its most fundamental level empathy depends upon perception. We have to see, or possibly to hear, others in order to view things from their point of view. Building a wall constrains who can see whom, and so can constrain the potential for empathic relationships. Thus, a simple enclosure of the kind illustrated in Figure 1. defines two quite distinct regions of the ground plane. In the interior of the enclosure everyone can see everyone else. If A can see B, and B can see C, then A can see $\mathrm{C}$. This is a consequence of the convexity of the enclosed space, and maps onto a potential symmetry of social relations. The same does not hold for A', B' and C' in the immediate exterior vicinity of the building where the building hides each from the other. Interestingly, if C' moves away from the building to C" there comes a point where both A' and B' are visible to C'. The effect of the building on the relations between A, B and C is relative to their positions in space with respect to each other and to the building. In this case while the three are inter-visible, the relationship between A' and B' passes through C" and so the relations are asymmetric, again mapping onto an asymmetry of social relations. C" has a 
privileged status with respect to information since she can see both A' and B' while they can only see her.

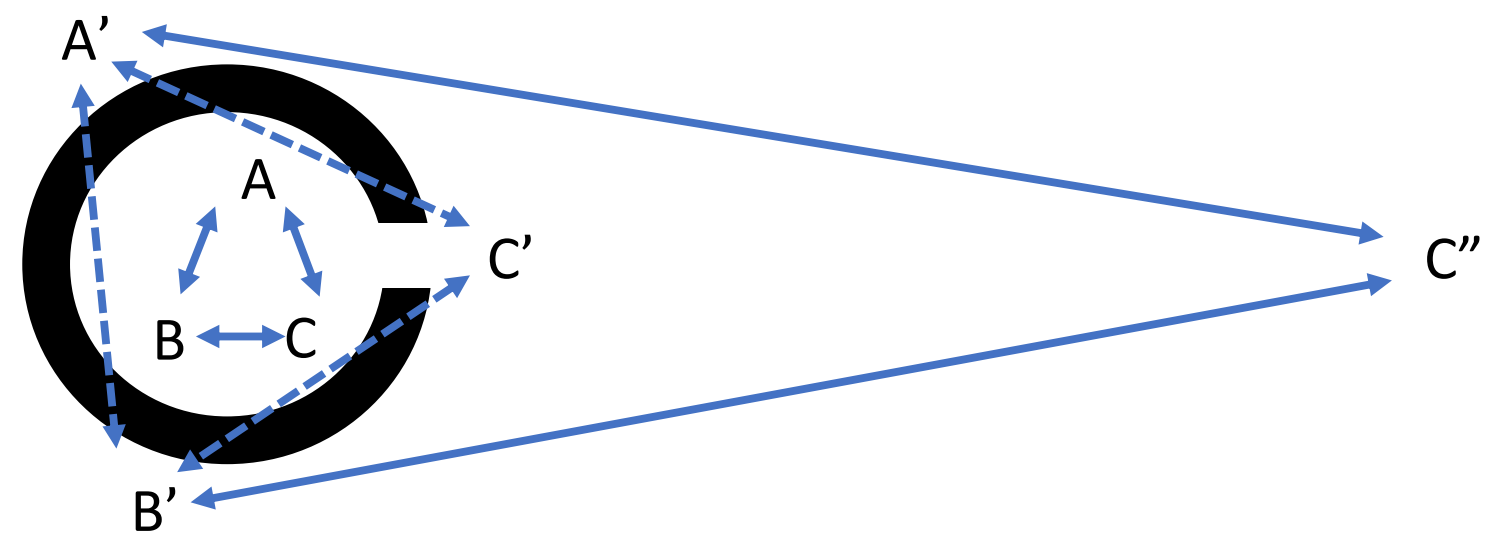

Figure 1. The effect of built form on potential social relations.

The Anatolian discovery was that when buildings are constructed sufficiently closely together the constraints on the distance C'-C" affects who can see who in the external realm. In this sense spatial configuration is intrinsically relational. The settlements that began to be built in Anatolia in the $9^{\text {th }}$ millennium BC were densely packed together. In Aşıklı höyük for example, one of the earliest of these settlements for which there is good archeological evidence, the structure of the external realm appears to have been complex, involving access across roof terraces since individual dwellings were entered through a roof level opening. As buildings were built right next to each other, however there also appears to have been a system of alleyways and a larger scale street at ground level (Todd, 1966, Owen, 2008). It seems possible that these alleyways were there to provide access from the ground to the roof level terraces. In this way the external realm began to take on the structure of convex enclosure, axial alignment and symmetry/asymmetry of visibility. This in turn would be expected to have constrained and generated the potential for social relations of occupants and passers-by in the external urban realm.

\section{Constructing social interfaces}

One of the most direct effects this structure might be expected to have had was on the potential for relations between two groups of people, the inhabitants of dwellings in the settlement, and those who were visiting or passing through from surrounding settlements and from further afield. This 'inhabitant-visitor interface' would have been constructed in two forms: by the spatial configuration of the external realm and its effects on movement and on co-presence in space; and, through the way that building entrances related to these patterns of movement. In the case of the early Anatolian settlements entrances appear mainly to have been at roof level. This would have been affected, in turn, by patterns of spatial clustering or dispersion of different social or functional groups in the community. 


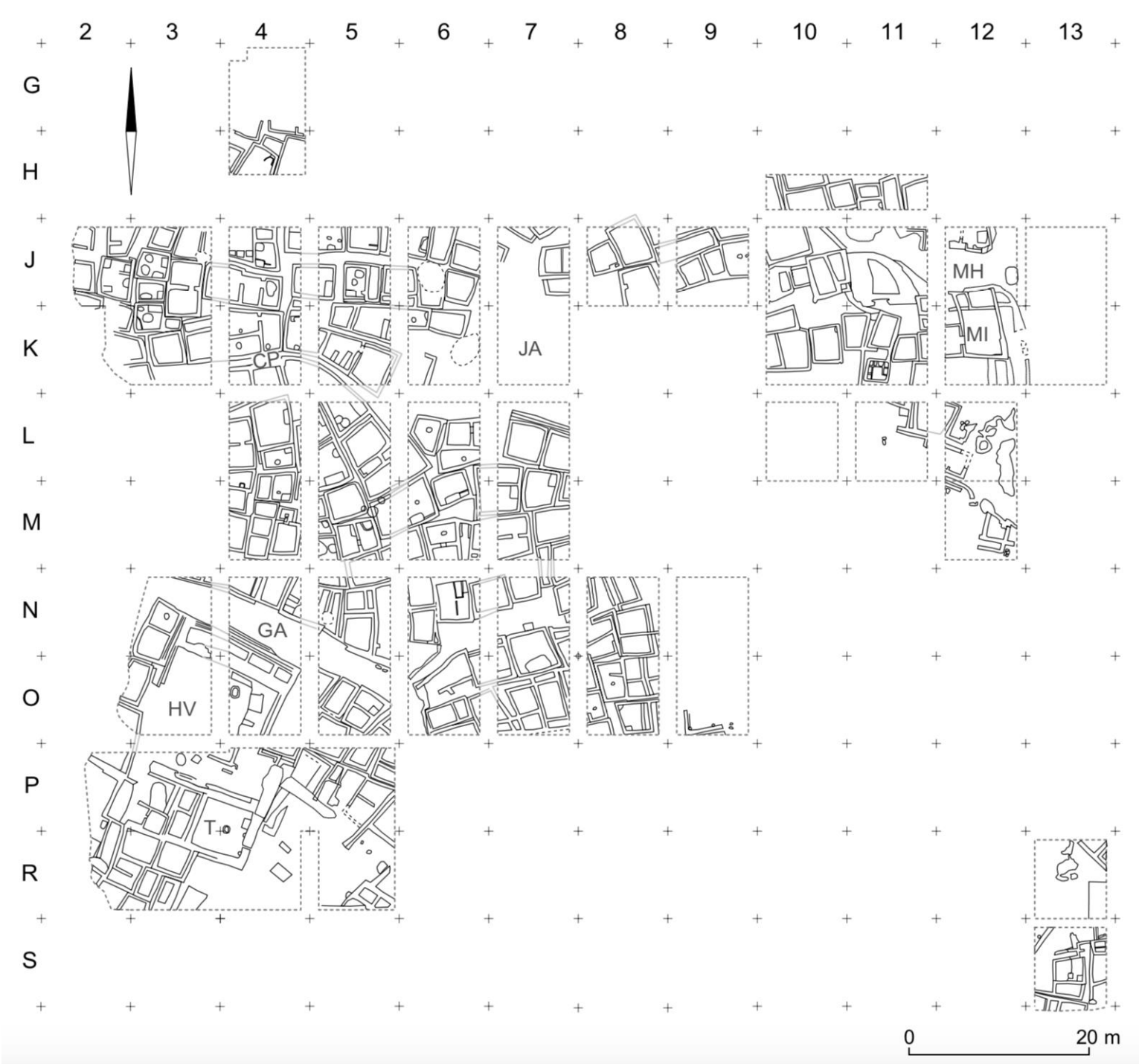

Figure 2. Composite plan of Aşıkl Höyük layers 2A-C (trench 4H/G is layer 2B). Based on figures 3 and 10 in Esin and Harmankaya 1999, (Figure 4.1: from Düring, 2006, with permission of the author.)

Jane Jacobs suggests that a possible driving force behind the formation of these earliest settlements was to support trade (Jacobs, 1969). She suggests this might have been trade in obsidian, and this is indeed supported by the archaeology. Evidence has been found in Aş1kl1 höyük for example for mass production of obsidian tools and one theory is that it may have effectively operated as a Neolithic 'factory' (Düring, 2006). If Jacobs is correct that trade was the driver, then the inhabitant-visitor interface would have been the main mechanism through which this operated. She goes on to argue that settlement then catalysed specialisation in production and a division of labour, for example in the production of obsidian tools, and eventually in the domestication and production of wheat. As soon as a society has a division of labour, trade becomes a key aspect of everyday life since specialisation in the production of one commodity, although creating efficiencies, leaves one in need of other commodities. It is then not a long step between exchange and the need for writing to make a record and to make credit and currency possible, and so to a full economy. This in turn requires mechanisms to resolve disputes and so the apparatus of the state, law and government. Government depends in turn upon the acquiescence of the mass to the dictates of a ruling elite, but this too requires that the elite maintain its legitimacy. 
Both economies and polities are driven in part through self-reinforcing feedback processes of this kind. In the case of a division of labour in production, spatial clustering seems to emerge to support exchange. There is a substantial literature discussing the economies of agglomeration that may account for this kind of clustering, however, one hypothesis is cognitive. Exchange requires those in search of some kind of goods to be able to find the provider of these goods. Search in this case is a cognitive process, depending upon the searcher having some idea where to begin looking, and so some kind of 'cognitive map' of the likely disposition of goods in their environment. Equally, the supplier of the goods is more likely to succeed in exchanging them if they locate themselves somewhere those searching are likely to pass by.

There is considerable and growing evidence supporting the existence of a cognitive map in the brain, based on place cells (O'Keefe \& Nadel, 1978) head direction and grid cells (Sargolini et al., 2006). The contention I make in this paper, however is that by structuring the configuration of the environment itself, as well as the location of salient features in that environment, processes of production of the built environment have developed as an externalisation of the cognitive map. The clearest example of this is described by Hillier et al (1987) where they identify consistent second order measures of cities and urban areas in terms of the correlation of first order configurational variables. They define 'intelligibility' as the correlations between local measures of the axial graph, such as connectivity, with global measures such as integration (closeness centrality). The inference is that in an environment where local-global correlations exist an individual can learn to use their local perceptions to inform their understanding of where they are in global terms. In an environment where local and global are not correlated, this learning will not be possible, and inhabitants will need to develop a higher degree of competence in order to locate themselves, and so to intervene purposefully in the world.

\section{Embodied cognition and search}

I have written previously about the effects of forward facing vision on movement choices and search. Having eyes in the front of our heads, like our inability to fly or move through solid walls, is another human universal. A simple example illustrates the effect this has. Alasdair Turner and I developed a simulation in which computational agents were given a very simple movement rule: to select at random a point within their visual field, to turn towards this and move forward three steps, and then to repeat the process. The simulation allowed the angular field of view of the agent to be set anywhere between a full $360^{\circ}$ and $11^{\circ}$ tunnel vision. This simulation was, in effect, a stochastic sampling of a visibility graph, but with the potential for an anisotropic, forward facing, function (Turner \& Penn, 2002). Comparisons between observed pedestrian movement patterns in urban areas and computational simulations with varying angular fields of view found the highest correlations to occur at around $135^{\circ}$, approximately the human field of view. In relatively confusing environments such as the IKEA showroom (Figure 3) we found that the agents' movement correlated well with observed shopping movement patterns (Penn, 2005). 

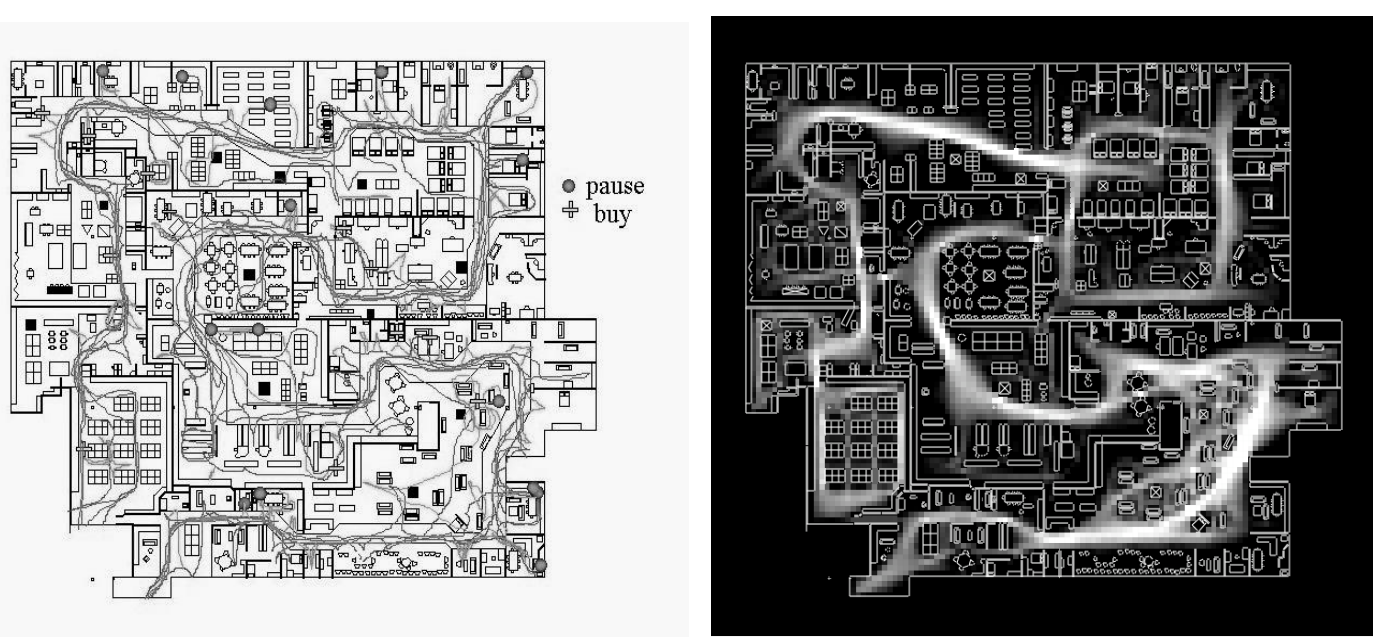

Figure 3. Observed shopper movement (left), and visual agent movement (right).

Further experiments using these agents have demonstrated that clustering of 'shops' in space supports more efficient search amongst mobile sighted agents where specific goods are being sought (Penn \& Turner, 2004). We created a series of experimental environments in which we located a fixed number of 'shops' each offering different 'goods'. Agents were given a desire for a specific category of goods and were set to search a given number of shops to find the best choice of goods to match their desire. We then timed how long it took the agents to find what they were looking for under a series of different geographies of distribution of shops in the environment. Different sizes and locations of cluster were shown to support search for multiple commodities with different degrees of efficiency depending on the degree of intelligibility of the urban configuration, where intelligibility is measured in the way described above.

These experiments suggest not only that our cognition is embodied, in that it is directly related to aspects of our anatomy, but also that it is embedded. This is in the sense that one cannot account for cognition purely in terms of the cognizing subject without invoking an account of the environment within which they exist. The structural properties of that environment affect the way that we move through and experience it, and since the environment is shared in common between different individual occupants, it acts as a shared aspect of our common cognitive experience.

\section{The nature of social evolution}

I have suggested that the history of human progress is characterised by a series of feedback loops which in some sense are self-reinforcing. For example, as we move from a subsistence economy to a modern economy there is an increase in specialisation and the division of labour. Once a society has embarked on this trajectory it is extremely hard for it to go back, short of a major catastrophe, such as plague or war in which existing social structures are effectively destroyed, all the social and economic pressures tend to show path dependency. Social evolution appears to have a ratchet mechanism that prefers development in one direction. Specialisation and a division of labour in turn require coordination and transaction to work, and this in its most general terms requires some kind of governing elite to take on that task on behalf of society. Again, an elite once created is likely to persist, or in the case of revolution or conquest, to be replaced by another elite of a similar form. So far as ruling elites go "plus ça change, plus c'est la même chose" appears to be a universal law. 


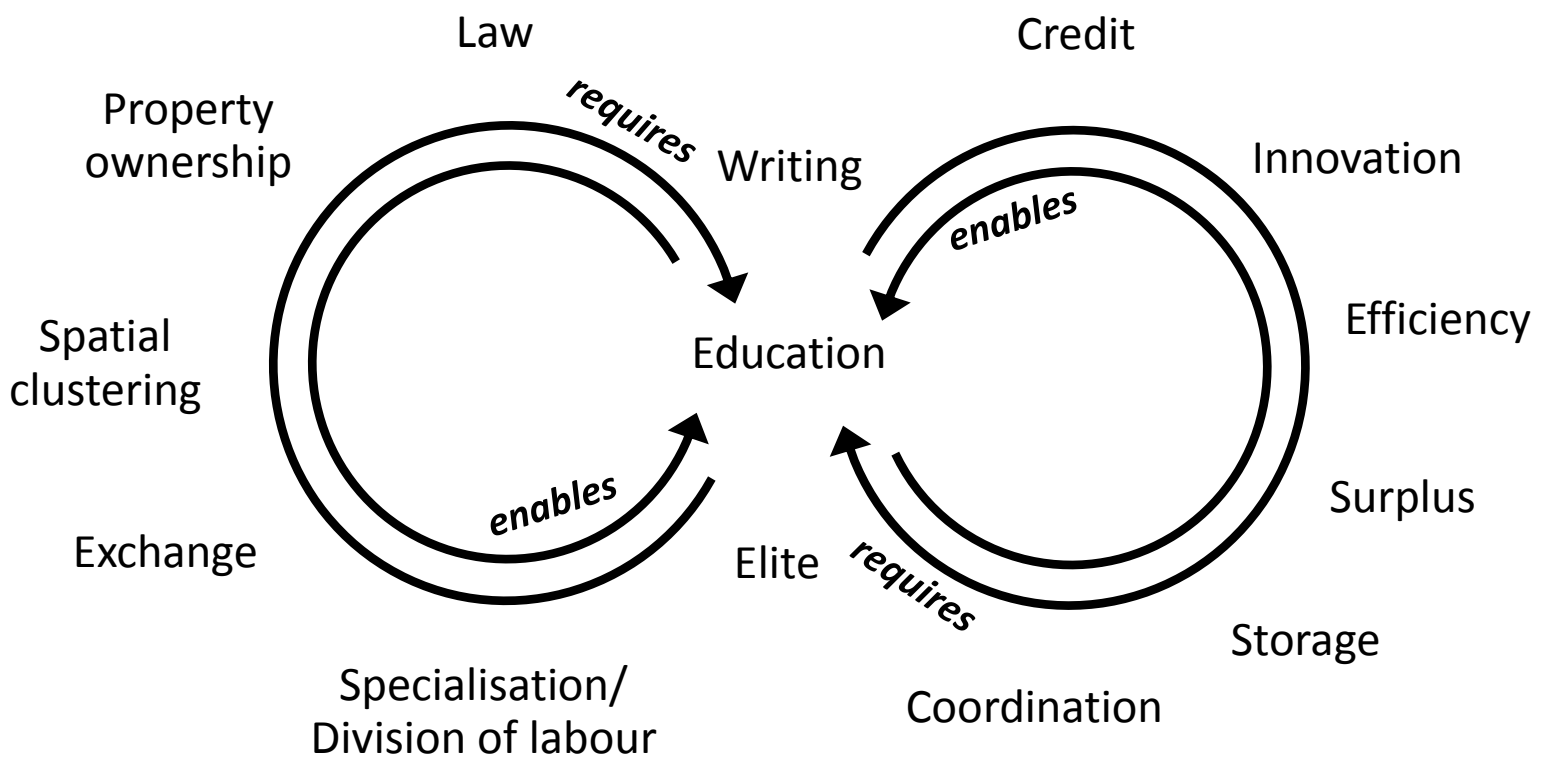

Figure 4. Cycles of feedback and reinforcement: spatial clustering requires property ownership which requires law. Conversely, law enables ownership which enables clustering. The two cycles are held together through a common dependency on writing, education and the development of an elite.

The mode through which these forms operate and are conserved, however, seem to vary. There are, for example, at least two characteristically different modes through which coordination can be achieved; through management diktat or through the operation of markets. Management relies on the legitimacy of the managing elite which ultimately depends upon the ability of leaders to communicate their vision to the population and to keep that population in agreement with their decisions. Again, there is more than one way to do this. Despots may achieve acquiescence through force, while liberals may use rational argument and an appeal to common values by 'winning hearts and minds'. Ultimately, management considered this way is emotional, acting through fear or favour, although it may often appeal to rational argument to justify its actions, or self-interest to achieve its ends.

Markets operate differently. Since their dynamic is not embodied in any single individual, they arise out of the interaction between many different individuals and so act statistically. This statistical process can be described essentially according to rational laws. This is not to say that the motivations or actions of the individuals who compose a market are rational. They are often driven to act by emotions, or on the basis of beliefs informed by emotion, but this does not matter, for the market as a whole will behave according to the statistical outcome of the (perhaps non-rational) actions of its many members. While markets can display crises of confidence or bubbles in trade which may appear irrational, we would now recognise these phenomena as the system dynamic outcome of feedback processes, and so open to rational explanation after the fact, although possibly non-deterministic or chaotic, making it hard to predict when they will occur in advance.

The operation of property markets and the dynamics of pedestrian space use also appear to be the statistical outcome of distributed processes, and so also 'rational' in this sense. It is 
central to my argument that this is the case: the space of the city is rational in its function and is open therefore to rational examination and explanation. However, the production of an urban spatial configuration in the first place, results from two possible processes. In the case of informal and traditional 'architecture without architects' the process is distributed amongst many actors. While it may be rule governed as Hillier and Hanson (1984, p55ff) have suggested for the 'beady ring' settlements in the Vaucluse, these rules operate as restrictions on otherwise random processes of aggregation and are therefore again open to rational explanation.
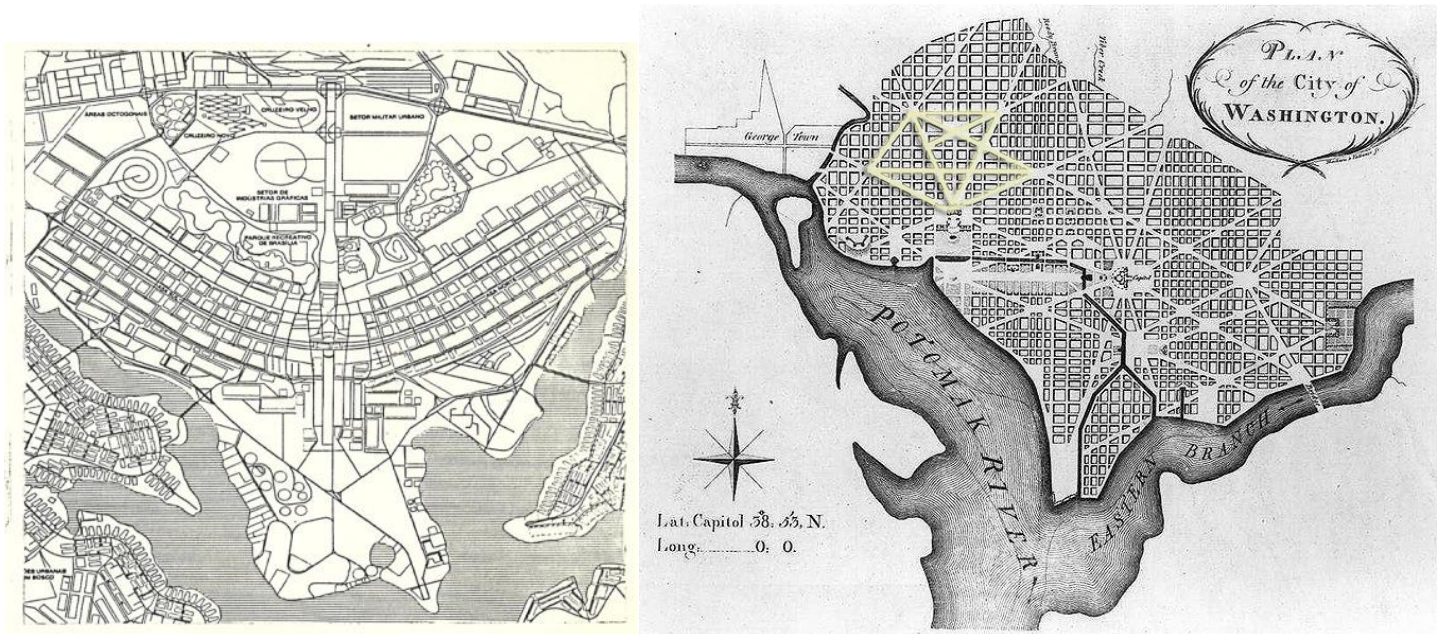

Figure 5. Symmetry, regular grids and axes all require regulation and management and so are indicative of central control and authority; (left) Brasilia's plano Piloto; (right) $L$ 'Enfant's plan for Washington DC.

Planned urban settlements, however are constructed according to a vision defined by a designer or masterplanner. They embody, often through symbolic association, the aspirational values, theories and beliefs of those that commission them. This form of planning itself requires coordination and control. It requires for its construction (and so indicates the presence of) a hierarchical form of polity governed by a ruling elite, and it manifests itself in scale of space, regularity of grids and geometric coordination such as spatial hierarchies or symmetries. Planned Capital cities from Brasilia to Washington DC demonstrate this in abundance (Figure 5).

Regardless of whether an environment has been produced by a planned or an unplanned process, it is clear that the effect upon the users of space emerges largely from distributed processes and so is open to system dynamics, as well as, in principle, to rational explanation. However, the way in which space is used is also subject to control by a strong government since both markets in land and traffic flows may regulated. It is clear that the only reason to regulate is if one wishes to achieve a different pattern of use to that which would arise in an unregulated market or traffic system, and so in these cases regulation must act as a constraint on a purely statistical outcome. From this point of view, it is possible to consider the affordances of any structure (let's say the spatial configuration of a city or the structure of governance of an institution) to accept regulation. Social rules on behaviour or space use can also apply differently to different categories of people, for example by gender, social class, caste, creed or division of labour. This will have the effect of differential patterns of occupancy, presence and encounter between these different categories, and so acts as a potential mechanism to construct differential social solidarities within different groups and so to perpetuate these social distinctions. 
The motivation for regulation can be instrumental or symbolic. If traffic is regulated in order to avoid congestion or a market is regulated to avert market failure, these might be classed as instrumental. Where streets are closed to allow passage of the entourage for a state occasion the action is largely symbolic; to interrupt everyday life as a manifestation of the power of the state, although often an instrumental explanation such as 'to maintain the security of VIP's' may be used. A specific example of this expression of class power is given by Hanson and Hillier's (1987) analysis of post-war housing. They showed how systematic planning of the urban realm, ostensibly to create community structure through enclosure, and repetition of hierarchies of public to private space, in fact created isolated and unintelligible estates which then, through a process of housing allocation to the poorest, and mobility of those with the capacity to gain employment, led to a sink estate phenomenon (Hillier, 1986; Hillier et al. 1989).

The question of whether this last example is of the symbolic expression of power, or an instrumental suppression of one class by another must remain open to debate. However, since the built environment is solid, physical and empirically present it acts to ground-truth both the emotional and the rational forms of human behaviour. Since it is shared in common between individuals it can effectively act to coordinate groups, and since it intervenes between individuals and groups it can structure the statistical interactions of markets and other institutions. It can also be interpreted as 'meaningful' and so is open to both rational discussion and symbolic action in its own right. The construction of settlements requires coordination and so must have been a driving force for development of political structures. The more advanced a society, the greater the span of control of the built environment. Hillier and Hanson's beady ring settlements, for example, merely require local coordination essentially neighbours need to agree to share walls and not to block access through open space - while the construction of a symbolic axis in a masterplanned capital requires building facades to be aligned over very long distances, possibly across the whole diameter of the city. This has two effects. First, it makes clear the presence of a coordinating authority and so is symbolic of the power of the governing elite. Second, it creates a single space which is connected across a large section of the city and so lies on many simplest routes between multiple locations, and so plays an important instrumental role. L'Enfant's diagonals in Washington DC are a case in point. It is no coincidence that when any of these axes are closed to allow a state procession, this act has a significant effect on everyday life. This kind of space therefore plays a role, both symbolic and instrumental (Hillier, 1996, p218ff); playing in both the emotional and rational domains.

\section{A hypothetical mechanism behind social evolution}

Here we arrive at the nub of the mechanism. Humans act purposefully to achieve instrumental ends; in their behaviours, in the artefacts and environments they construct, and in the social rules imposed upon the use of space and the behaviour of members of a society. At the same time, humans also make meaning. Even where apparently no intentional meanings exist, we are apt to hypothesise and read meanings and intent into even the most innocent of coincidences or natural phenomena. As we have seen this is the basis of storytelling and the active engagement of the listener in the construction of meaning. I suggest that this ability to imagine possible future worlds whose existence would give an apparent purpose to social and physical structures, serves to turn teleology on its head. No longer do we merely explain a phenomenon in terms of its purpose, but we imagine the future consequent upon the structures at hand. This forms a fundamental feedback loop between the way that we act or behave, and the way that we conceive the social world, not only giving it 
meaning, but building those meanings through the way that individuals move through and experience the world around them.

Not only are our behaviours context dependent in this way, but they are also contingent upon the meanings we ascribe to that context. This feedback loop between behaviour and meaning can only become social since it relates to the intersubjective realities of our physical and spatial environment and the overt behaviours and activities of other individuals of whom we are aware; an awareness itself shaped in large measure by the effects of spatial configuration described earlier. Meanwhile, our behaviours including their physical and social manifestations, are also read as meaningful by others and so influence their behaviour in turn. Thus, there is a continuous cycle of meaning informing behaviour and behaviour informing meaning, and it is through this cycle that the structure of the social form is continually reconstructed in the minds of the individual members of a society and acted out through the overt behaviours of those individuals in public space. Haken and Portugali (2015) deal exactly with this process. Following Weaver's original suggestion that semantic information could be incorporated into the theoretical framework of Shannon's original statistical definition, they develop a plausible mechanism to explain this 'meaning-behaviour-meaning' cycle and apply this to explain the adaptation of urban landscapes.

Spatial configuration appears to be directly implicated in this process. Our propensity to develop conspiracy theories, for example, offers evidence for this. Where one group is spatially isolated from another 'fear of the other' seems often to develop. Spatial and social segregation go hand in hand, and then act to reinforce each other. Conversely, where the configuration 'integrates' and brings together numerous different paths of individual activity into a single space, social distinctions commonly seem to be broken down. The market square overcomes social distinctions in the construction of a space of transaction. The key contribution of the physical environment in this is that it provides an intersubjective reality, and so grounds both physical behaviours and symbolic associations in a single reality that individual members of society can agree exists.

There are four components to any evolutionary mechanism. To use a computational analogy, first, it requires a means of 'writing to memory' some description of the current form; second, a means of reading back from memory and reconstructing that form, third a means through which novel variations of form are generated. Finally, it should be possible for more successful variations to be reproduced more easily. Here I propose that the configuration of the built environment, considered in the right way, has just these four properties when it comes to a consideration of social forms. As illustrated in Figure 1, the construction of spatial configuration bounded by walls, has direct effects on who can see whom, as well as on patterns of movement of people in space (Hillier et al, 1993), and thus on patterns of copresence. These patterns may be moderated or controlled by social rules on space use and access and so rule systems also affect the potential for co-presence and awareness. The pattern of spatial configuration of a settlement is created by the construction of individual buildings, and so these patterns act to 'record' the processes - social and economic - of the production of the built environment. Once produced, the act of inhabiting and using an environment by its numerous inhabitants creates the field of co-presence and awareness. Again, this will be moderated, for example by economic processes that lead to any form of functional or land use clustering, or to social rules on occupancy and behaviour. These rules and processes are thus made manifest in the real world of space, forming part of the intersubjective reality that individuals share in common. 
So far, I have described spatial patterns, but these patterns may also be played out in time through daily weekly and seasonal cycles, as well as through institutional synchronising events such as religious festivals or market days. It is the spatio-temporal phenomenon of lived lives, as it is shaped by the fabric of the city, that forms a manifestation of society. The configuration of that fabric also constrains the way in which this phenomenon is seen by members of society since it constrains who can see who, and from where, and this affects the way that meanings are constructed in the minds of the viewers. Institutions and regulation can also act to constrain the timing and synchronisation of events, as well as their locations, and in this sense both the spatial and temporal domains are subject to socially imposed rules.

It is clear that in the absence of rules, systems of this sort will perform largely according to the operation of statistics. However, the more that rules dictate any of the elements of the system; from the production of spatial configuration, through the allocation of social or economic functions to land parcels, to the control of movement and space use behaviours; the more the patterns of co-presence will be defined in advance and the opportunity for random interactions will be reduced. These 'longer model' systems will tend to conserve the social form that produced them, while shorter model systems will be more open to random innovation. Social systems therefore vary in terms of the degree to which they conserve existing forms or generate novel forms, and this property is embedded partially in the space of the settlement. However, it is also manifested in the space and its use patterns, and so subject to human interpretation and 'meaning making'.

I suggest that it might have been this combination of the emotional and rational that has driven human progress and social evolution, however the breakthrough came with the 'Anatolian discovery' where the space of our environment was found to mediate social relations as well as meaning making. Building on Michael Bratman's (1987) distinction between beliefs, desires and intentions as guides to our actions, by incorporating a spatial dimension, our beliefs about the world are essentially cognitive, our desires are emotional and so affective, while our intentions are rational and so evident in our behaviours. In spatial terms beliefs require intelligibility in the world. Unless we understand where we are and what we perceive we are in no position to hold a socially meaningful belief about the world. More precisely, although we may hold a belief, without an intersubjective reality upon which we can ground and share that belief, the relationship to other members of society's beliefs must remain arbitrary.

Desires are both social and environmental - they benefit from positive social relations and so awareness and enclosure, prospect and refuge. Awareness and enclosure are of course in tension, and it is one of the wonders of architecture that this tension can indeed be resolved. Bill Hillier has explained this most elegantly by showing how visual accessibility and movement accessibility take on complementary patterns in space (Hillier, 1996, p339ff). Thus, the far corner of a room may command the best visual surveillance while the central area is the closest to all other locations. Similar tensions exist between the axis as a symbolic device and as an instrumental construct described above. It is this ability for a single feature of the landscape to perform in diametrically opposite ways that marks out the architecture of the urban landscape as at the same time a generator and a conserver of social forms. Those social forms, in turn are generated and conserved both as instrumental phenomena in the world and as mental constructs in the minds of the occupants, so shifting the 'stuff' of society into a material which could be imagined and shaped through the combined actions of all the individuals in a social group. In a recent paper co-authored with Scott Turner (Penn \& Turner, 2018) we discussed by analogy with the termite mound the notion that the 
environment of the nest is itself an active physiological regulator for the termite 'superorganism'. We suggested that the most far reaching effect of the 'Anatolian discovery' may have been to create a human 'super organism' whose action, rather than to maintain physiological homeostasis, was on the generation and reproduction of social forms by exerting systematic effects on distributed cognition. The mental and the lived physical worlds thus united and shared inter-subjectively, are made social and real in the 'city as knowledge'.

Here we have a possible mechanism to account for the persistence over multiple generations of social forms, at the same time as the evolution of these within a single lifetime to create radically new forms. It allowed successful social structures to conserve their form and for problematic structures to evolve and change. Perhaps it was this discovery that accounts for the step change in the pace of human progress around 10,000 BC.

\section{References}

Bohn, M., Call, J., Tomasello, M. (2015), Communication about absent entities in great apes and human infants, Cognition, Volume 145, 2015, Pages 63-72, ISSN 0010-0277, doi.org/10.1016/j.cognition.2015.08.009.

Bratman, M. E. (1999) [1987]. Intention, Plans, and Practical Reason, CSLI Publications, ISBN 1-57586-192-5

Clark, A. \& Chalmers, D., (1998), The Extended Mind, Analysis, Volume 58, Issue 1, 1 January 1998, Pages 7-19, https://doi.org/10.1093/analys/58.1.7

Cooper, A. \& Stringer, C.B., (2013), Did the Denisovans Cross Wallace's Line?

Science 18 Oct 2013: Vol. 342, Issue 6156, pp. 321-323; DOI: 10.1126/science.1244869

Dalén, L., Orlando, L., Shapiro, B., Brandström-Durling, M., Quam, R., Gilbert, M.T, Díez Fernández-Lomana, J.C., Willerslev, E., Arsuaga, J.L., Götherström, A., (2012), Partial Genetic Turnover in Neandertals: Continuity in the East and Population Replacement in the West, Molecular Biology and Evolution, Volume 29, Issue 8, 1 August 2012, Pages 1893-1897, https://doi.org/10.1093/molbev/mss074

Donald, M. (2017), Key cognitive preconditions for the evolution of language, Psychon Bull $\operatorname{Rev}(2017)$ 24: 204. https://doi.org/10.3758/s13423-016-1102-x

Düring, B.S., (2006), Constructing communities : clustered neighbourhood settlements of the Central Anatolian Neolithic ca. 8500-5500 Cal. BC, Nederlands Instituut voor het Nabije Oosten, Doctoral thesis, Faculty of Archaeology, Leiden University.

Fukuyama, F., (2011), The Origins of Political Order: From Prehuman Times to the French Revolution. New York: Farrar, Straus and Giroux.

Hacken, H. \& Portugali, J., (2015), Information Adaptation: The Interplay Between Shannon Information and Semantic Information in Cognition; SpringerBriefs in Complexity, London: Springer. 
Hanson, J; Hillier, B; (1987) The architecture of community: some new proposals on the social consequences of architectural and planning decisions. Architecture et Comportement/Architecture and Behaviour , 3 (3) 251 - 273.

Hillier, B \& Hanson, J., (1984), The Social Logic of Space, Cambridge: CUP, ISBN 0-521-233658

Hillier, B; (1986) City of Alice's dreams. Architects' Journal, 9 July, 1986, p39-41

Hillier, B; Burdett, R; Peponis, J; Penn, A; (1987) Creating Life: Or, Does Architecture

Determine Anything? Architecture et Comportement/Architecture and Behaviour , 3 (3) pp. 233-250.

Hillier, B.; Jones, L.; Penn, A.; Jianming, X.; Grajewski, T.; (1989) The architecture of the Maiden Lane Estate: a second opinion. London: University College London http://discovery.ucl.ac.uk/1751/1/hillier-etal89-maidenlane.pdf

Hillier, B; Penn, A; Hanson, J; Grajewski, T; Xu, J; (1993) Natural Movement - or, Configuration and Attraction in Urban Pedestrian Movement. ENVIRON PLANN B , 20 (1) 29 66.

Hillier, B., (1996), Space is the Machine, Cambridge: CUP, ISBN 0-521-56039-x

Humphries, N.K., (1976), The social function of intellect, in Growing Points in Ethology, eds. P.P.G.Bateson \& R.A.Hinde, pp. 303- 317, Cambridge University Press, Cambridge, 1976.

Jacobs, J. (1969) The Economy of Cities, NY: Random House.

Jolly, A, (1966), Lemur social behavior and primate intelligence. Science, 153, 501-506.

Joordens, J., d’Errico, F., Wesselingh, F., Munro, S., de Vos, J., Wallinga, J., Ankjærgaard, C., Reimann, A., Wijbrans, J., Kuiper, C., Mücher, H., Coqueugniot, H., Prié, V., Joosten, I., van Os, B., Schulp, A., Panuel, M., van der Haas, V., Lustenhouwer, W., Reijmer, J. \& Roebroeks, W., (2015), Homo erectus at Trinil on Java used shells for tool production and engraving, Nature volume 518, pages 228-231 (12 February 2015); doi:10.1038/nature13962

Kirsh, D. (2010a), Thinking with External Representations. Al and Society. London: Springer, 25:441-454.

Kirsh, D (2010b), Explaining Artifact Evolution. In: Malafouris, L. and Renfrew, C. (eds.) The Cognitive Life of Things: Recasting the boundaries of the mind. Cambridge: McDonald Institute for Archaeological Research.

Korotayev, A, (2006), The World System Urbanization Dynamics: A Quantitative Analysis in (eds) Turchin, P., Grinin, L., de Munck, V., Korotayev, A., History \& Mathematics: Historical Dynamics and Development of Complex Societies, p. 44-62, Moscow: KomKniga/URSS. 
O'Keefe, J. \& Nadel, L., (1978) The Hippocampus as a Cognitive Map, Oxford: OUP.

Marie-Laure Ryan, (1991), Possible worlds, artificial intelligence, and narrative theory, Bloomington: Indiana University Press.

Owen, B., (2008), Examples of the first towns on Earth: Asikli H.yük and Çatal Hüyük, Emergence of Civilizations / Anthro 341: Notes 8. Available at:

http://bruceowen.com/emciv/a341-09s-08-AsikliHoyukCatalHuyuk.pdf

Penn, A. \& Turner, A. (2004), Movement-generated land-use agglomeration: simulation experiments on the drivers of fine-scale land-use patterning, URBAN DESIGN International (2004) 9, 81-96, Palgrave Macmillan.

Penn, A., (2005), The complexity of the elementary interface: shopping space, Proceedings of the $5^{\text {th }}$ International Space Syntax Symposium, TU Delft.

Penn, A. \& Turner, J.S., (2018), Can we identify general architectural principles that impact the collective behaviour of both human and animal systems? Phil. Trans. R. Soc. B 20180253. dx.doi.org/10.1098/rstb.2018.0253

Portugali, J., (2011), Complexity, Cognition and the City (Understanding Complex Systems), Berlin: Springer-Verlag, 2011, ISBN 9783642194504

Sargolini, F.; Fyhn, M.; Hafting, T.; McNaughton, B. L.; Witter, M. P.; Moser, M. -B.; Moser, E. I. (2006). "Conjunctive Representation of Position, Direction, and Velocity in Entorhinal Cortex". Science. 312 (5774): 758-762.

Todd, I. A. (1966), Aşıklı Höyük - A Protoneolithic Site in Central Anatolia. Anatolian Studies 16:139-163.

Turner, A., \& Penn, A., (2002), Encoding Natural Movement as an Agent-Based System: An Investigation into Human Pedestrian Behaviour in the Built Environment; Environment and Planning B, Volume: 29 issue: 4, page(s): 473-490.

Richerson, P., Boyd, R., Bettinger, R., (2001), Was Agriculture Impossible during the Pleistocene but Mandatory during the Holocene? A Climate Change Hypothesis, American Antiquity, Vol. 66, No. 3 (Jul., 2001), pp. 387-411 